\title{
Influence of Overloads on Dwell Time Fatigue Crack Growth in Inconel 718
}

\author{
Jonas Saarimäki, Johan Moverare, Robert Eriksson and Sten Johansson
}

\section{Linköping University Post Print}

\section{Tweet}

N.B.: When citing this work, cite the original article.

Original Publication:

Jonas Saarimäki, Johan Moverare, Robert Eriksson and Sten Johansson, Influence of Overloads on Dwell Time Fatigue Crack Growth in Inconel 718, 2014, Materials Science and Engineering: A, (612), 398-405.

http://dx.doi.org/10.1016/j.msea.2014.06.068

Copyright: Elsevier

http://www.elsevier.com/

Postprint available at: Linköping University Electronic Press

http://urn.kb.se/resolve?urn=urn:nbn:se:liu:diva-109348 


\title{
Influence of overloads on dwell time fatigue crack growth in Inconel 718
}

\author{
Jonas Saarimäki ${ }^{\mathrm{a}, *}$, Johan Moverare ${ }^{\mathrm{a}, \mathrm{b}, *}$, Robert Eriksson ${ }^{\mathrm{a}, *}$, Sten \\ Johansson ${ }^{\mathrm{a}, *}$ \\ ${ }^{a}$ Division of Engineering Materials, Department of Management and Engineering, \\ Linköping University, SE-58183 Linköping, Sweden \\ ${ }^{b}$ Siemens Industrial Turbomachinery AB, Materials Technology, SE-61283 Finspång, \\ Sweden
}

\begin{abstract}
Inconel 718 is one of the most commonly used superalloys for high temperature applications in gasturbines and aeroengines and is for example used for components such as turbine discs. Turbine discs can be subjected to temperatures up to $\sim 700{ }^{\circ} \mathrm{C}$ towards the outer radius of the disc. During service, the discs might start to develop cracks due to fatigue and long dwell times. Additionally, temperature variations during use can lead to large thermal transients during start-up and shutdown which can lead to overload peaks in the normal dwell time cycle. In this study, tests at $550{ }^{\circ} \mathrm{C}$ with an overload prior to the start of each dwell time, have been performed. The aim of the investigation was to get a better understanding of the effects of overloads on the microstructure and crack mechanisms. The microstructure was studied using electron channelling contrast imaging (ECCI). The image analysis toolbox in Matlab was used on cross sections of the cracks to quantify: crack length, branch length, and the number of braches in each crack.
\end{abstract}

*jonas.saarimaki@liu.se +46 13281193 
It was found that the amount of crack branching increases with an increasing overload and that the branch length decreases with an increasing overload. When the higher overloads were applied, the dwell time effect was almost cancelled out. There is a strong tendency for an increased roughness of the crack path with an increasing crack growth rate.

Keywords: Nickel based superalloys, Fatigue, Fracture, Mechanical characterization, Electron microscopy

\section{Introduction}

In gas turbine development, engineers and manufacturers strive to optimize performance and efficiency. This is achieved through the use of superalloys, which enable high operating temperatures which can result in better efficiency.

Inconel 718 belongs to the more commonly used superalloys and is a polycrystalline Ni-Fe-base superalloy. Inconel 718 derives its strength from solid solution alloying elements and, more so, from gamma prime $\left(\gamma^{\prime}\right)$ and gamma double prime, $\left(\gamma^{\prime \prime}\right)$, precipitates. Other beneficial properties are good corrosion resistance and weldability.

The alloy is frequently used for high temperature components subjected to cyclic loading, particularly when there is a risk for fatigue and creep deformation, such as turbine discs for land based gas turbine engines. Turbine discs can be subjected to temperatures up to $\sim 550{ }^{\circ} \mathrm{C}$ in land-based gas turbines and up to $\sim 700{ }^{\circ} \mathrm{C}$ in jet engines at which the mechanical properties starts to degrade [1].

Aircraft turbine engines can be exposed to overloads caused by unusual 
service conditions, e.g. harsh weather, turbulence or rough landings; whilst land-based gas turbines may be exposed to overloads initiated by the malfunctioning of other components that leads to unexpected stops. Primary overloads can also occur on a more regular basis, these are ordinarily detected in gas turbine components due to strong thermal transients during turbine start-up. Aircraft turbine engines, on the other hand, are pushed to their limits for shorter periods of time during take-off and landing while, at cruising speed, the loading is considerably lower.

The turbine is subjected to several different damage and fracture modes such as fatigue, creep, and oxidation. These fracture modes can be tested with different cycles that are often simplified in lab-tests when used for life assessment. One of these cycle types is the overload dwell time cycle [2], which is the focus of this paper.

Previous studies [3-5] have shown that Inconel 718 mainly cracks transgranularly during cyclic testing in the lower temperature range and intergranularly during fatigue at higher temperatures and with dwell times. The same behaviour has been observed in other superalloys such as Waspalloy [6]. Grain boundary embrittlement has been studied by Ref. [6-8] where it was shown that the crack growth per cycle during unloading-reloading is much higher after a dwell time period compared to pure cyclic loading. Similar observations has been reported to occur during thermomechanical fatigue crack growth tests [9]. Other crack growth mechanisms, such as dynamic recrystallization, strain localization in persistent slip bands, deformation bands, and vacancy diffusion, have also been proposed in references [10-14]. The purpose of this study is to examine the effects of dwell times and overloads on 
the crack growth mechanisms in Inconel 718. This is important and needed to enable more reliable fatigue life calculations for structures subjected to complex loadings.

\section{Experimental procedure}

The material used in this study was standard heat-treated Inconel 718

according to AMS 5663; solution anneling for 1 hour at $945{ }^{\circ} \mathrm{C}$, followed by aging for 8 hours at $718{ }^{\circ} \mathrm{C}$ and 8 hours at $621{ }^{\circ} \mathrm{C}$. It had a chemical composition as shown in Table 1 and an average grain size of $10 \mu \mathrm{m}$.

\subsection{Fatigue testing}

\subsubsection{Specimens}

Fig. 2, shows an instrumented Kb-type test specimen that was used for all tests with a rectangular cross-section of $4.3 \times 10.2 \mathrm{~mm}$ and an electrodischarge machined starter notch measuring: depth $0.075 \mathrm{~mm}$, width 0.15 $\mathrm{mm}$, and length $0.3 \mathrm{~mm}$. One specimen was used for each test condition.

\subsubsection{Experimental details}

A fatigue pre-crack was propagated at room temperature by using a load ratio of $R=\sigma_{\text {min }} / \sigma_{d w e l l}=0.05$, and a cyclic frequency of $10 \mathrm{~Hz}$ which resulted in a semi-circular crack with a depth of approximately $0.2 \mathrm{~mm}$ before the high temperature was applied and cycling was started. After which, the specimens were subjected to: 1) pure fatigue at $0.5 \mathrm{~Hz}, 2$ ) fatigue with a high-temperature dwell time and 3) fatigue with a high-temperature dwell time and overloads. The overload was always applied before the dwell time 
part of each cycle as illustrated in Fig. 1. The overload level, OL, was calculated as

$$
O L=\frac{\Delta P_{\text {unloading }}}{P_{\text {dwell }}}
$$

with $\Delta P_{\text {unloading }}$ and $P_{\text {dwell }}$ defined in Fig. 1.

All overload tests were done in laboratory air at $550{ }^{\circ} \mathrm{C}$ with overloads of 2.5, 5.0, and $15 \%$ followed by a 2160 s dwell time using Kb-type specimens with a semi-cirkular crack.

Crack growth was measured according to ASTM E 647 using a 12 A channel pulsed DCPD (Direct Current Potential Drop) system. Crack length was calculated by dividing the potential drop (PD) over the crack by the PD on the opposite side as a reference. This ratio was then converted to crack length assuming a semi-circular crack front via an experimentally acquired calibration curve for Inconel 718 which showed the PD ratio as a function of crack length based on the initial and final crack lengths measured on the fracture surface as well as by measured induced beach marks [15]. The analytical solution for the stress intensity factor, K, was obtained using a pre-solved case for a semi-elliptic surface crack according to ASTM E740-03. When a crack length of $2.5 \mathrm{~mm}$ was reached, according to the $\mathrm{PD}$ value, the test was interrupted. Testing was done using a $160 \mathrm{kN}$ MTS servo hydraulic tensile/compression testing machine, equipped with a three zone high temperature furnace. The nominal load during the dwell time was $\sigma_{\text {dwell }}=650$ $\mathrm{MPa}$ and all tests were conducted with the load ratio $\mathrm{R}=0.05$, as given by equation 2 . 


$$
R=\sigma_{\min } / \sigma_{d w e l l}=0.05
$$

\subsection{Microscopy and image analysis}

After fatigue testing, some specimens were cross-sectioned and mounted as-is, so that the crack path could be studied, while others were tensiled until fracture and used for studying the fracture surfaces. The cross-sectioned specimens were cut roughly at the center line of the semicircular crack. A Hitachi SU70 FEG analytical scanning electron microscope (SEM), operating at $1.5-20 \mathrm{kV}$ was used together with Electron Channelling Contrast Imaging (ECCI) [16] to get high quality, high contrast pictures of the crack growth appearance and the microstructure.

On the cross-sectioned specimens, the crack path was identified through image analysis and characterized by a number of parameters such as crack path length, mean crack branch length and number of branches; when necessary (i.e. for crack path length and number of branches), the parameters were normalised by the horizontal crack path length to enable comparison of cracks of different lengths. Some measurements were performed without including crack branches, here referred to as the main crack.

In addition, the crack roughness (an $R_{a}$-like value), $C_{R}$, was calculated for each crack, quantifying the roughness of each crack where high $C_{R}$ indicated a rough crack path. A reference line was fitted to the crack and the crack path was then described by its distance from the mean line, $z(x)$, see Fig. 3. $C_{R}$ was calculated as

$$
C_{R}=\frac{1}{L} \int_{0}^{L}|z(x)| d x
$$


where $L$ is the projected crack path length.

The $C_{R}$ was calculated for an unmodified crack path and, as is common for $R a$, filtered crack paths. The filtering was conducted using a Gaussian high-pass filter which passes wavelengths shorter than the cut-off wavelength, $\lambda_{c o}$. Several different $\lambda_{c o}$ were tried. Fig. 3 shows an example for $\lambda_{c o}=100$ $\mu \mathrm{m}$ where Fig. 3 a) shows the longwave component being removed and Fig. $3 \mathrm{~b})$ shows the filtered crack path. The unfiltered crack path gave a $C_{R}$ value which was influenced by large-scale kinks in the crack path while the filtered crack path gave a $C_{R}$ value dominated by small-scale kinks in the crack path (i.e. unaffected by large-scale kinks).

\section{Results}

\subsection{Crack growth rate}

In Fig. 4, crack growth rate is plotted versus the stress intensity factor range $\Delta K$ for: $2.5,5.0,15 \%$ overloads, 2160 s dwell time, and a baseline test without dwell time. Overloads had a significant effect on the crack growth rate, even at low overloads such as $2.5 \%$. For the $15 \%$ overload test the crack growth rate decreased by a factor of $\sim 100$ compared to the $2160 \mathrm{~s}$ dwell time test and almost cancelled the dwell time effect.

\subsection{Cracking behaviour}

Fig. 5 shows the appearance of the crack path on cross-sectioned specimens for the $2160 \mathrm{~s}$ dwell time test, overload tests, and the base-line test. For the dwell time test and for low overload, the cracking was dominantly intergranular; for the baseline test and the higher overloads, the cracking was 
transgranular. The cross-sections also revealed that there was more crack branching with an increasing overload.

Fig. 6 shows the fracture surfaces from the fatigue tests. The baseline fatigue test gave transgranular fracture, as evident from the presence of striations, whereas the specimen subjected to a $2160 \mathrm{~s}$ dwell time without overloads failed through intergranular fracture, see Fig. 6 a) and e) respectively. When overloads were applied, in addition to dwell time, the fracture mechanism changed from intergranular to transgranular with increasing levels of overload, as seen in Fig. 6 b)-d). The most obvious difference in fracture mechanism occurred between $2.5 \%$ and $5 \%$ overload.

The crack growth behaviour was further studied by image analysis. Fig. 7 shows a short section of the crack in the $2160 \mathrm{~s}$ dwell time specimen where the calculated crack path is illustrated by the yellow line. Fig. 8 a) shows the normalized main crack length; it dropped slightly for the overload specimens but remained fairly constant for the different overloads. Fig. 8 b) shows the normalised number of branches and the mean length of the branches. A higher overload increased the number of branches but decreased the mean branch length. As the overload increased from $2.5 \%$ to $15 \%$, the average branch length decreased from $\sim 8.5 \mu \mathrm{m}$ to $\sim 5 \mu \mathrm{m}$.

The main crack paths were further characterized by the crack roughness, $C_{R}$. Fig. $8 \mathrm{c}$ ) shows $C_{R}$ for an unfiltered crack path and for a filtered crack path with $\lambda_{c o}=100 \mu \mathrm{m}$. The $2160 \mathrm{~s}$ dwell time sample gave the highest $C_{R}$ and the pure fatigue condition gave the lowest. The $C_{R}$ decreased with increasing overload, more so if large-scale kinks were included in the measurements. The unfiltered $C_{R}$ dropped $\sim 50 \%$ for the $15 \%$ overload 
compared to the $2160 \mathrm{~s}$ dwell time test without overload. For the filtered $C_{R}$, where all wavelengths $>100 \mu \mathrm{m}$ were removed, the drop was $30 \%$.

\subsection{Crack mechanisms}

\subsubsection{No or low overloads}

For no or low overloads, high resolution scanning electron microscopy revealed that microscopic crack growth in Inconel 718 at high temperature took place as intergranular crack growth along grain boundaries due to oxidation and the creation of nanometric voids. The growth of pores in grainboundaries and intergranular fracture by growth of nano-sized pores can be seen in Fig. 9 a and b. Another observed growth mechanism was crack advance along $\delta$ phase boundaries with subsequent severe oxidation of the $\delta$ phase, see Fig. 10. Sometimes it was also possible to observe unbroken ligaments behind the crack front. At such locations, the crack eventually grew along the substructures created by severe local plastic deformation and the high temperature. This substructure consisted, of dislocation sub-cells or nanosized grains created by embryos to dynamic recrystallization which can be seen as black dots in Fig. 11.

\subsubsection{High overloads and baseline}

For high overloads and baseline tests the crack growth was mainly transgranular due to severe local deformation in front of the crack tip. For the test with a $15 \%$ overload, this typically led to a serrated crack path and crack tip blunting, as seen in Fig. 12 a). The distance between the serrations corresponded very well with the crack growth between two overload cycles. Thus, there was a tendency for crack branching during each overload 
cycle. The majority of the crack branches become blunted and only very few grows longer in the following cycles. The typical appearance of a blunted crack tip can be seen in Fig. 12 b). When the crack grows transgranularly, and through $\delta$ phases within the grains, the $\delta$ phases showed some degree of plastic deformation as seen in Fig. 13.

\section{Discussion}

The use of wrought fine grained polycrystalline nickel base superalloys, such as Inconel 718, are in many situations limited by their susceptibility to fast intergranular cracking during extended dwell times at high temperatures and high tensile stresses [9]. It has been well established that time dependent intergranular cracking of nickel-based superalloys, under both sustained and cyclic loads, is dominated by environmental interactions with oxygen at the crack tip $[8,17]$. Intergranular cracking is not due to the formation of massive oxidation products along the grain boundaries. The mechanism is better described as nano scaled dynamic embrittlement, where oxygen diffuses into highly stressed grain boundaries at the crack tip and causes decohesion $[18$, 19].

Previous studies $[20,21]$ have shown that complex oxides of $\mathrm{Ni}, \mathrm{Cr}$, and $\mathrm{Fe}$, as well as oxides formed from niobium carbides, can be formed at the crack tip in Inconel 718. This conforms with our observations where it can be seen that the crack growth rate at $550{ }^{\circ} \mathrm{C}$ increased by a factor of 100 when a dwell time of $2160 \mathrm{~s}$ was applied at the maximum load, see Fig. 4. When a dwell time was applied, the crack growth changed from transgranular to intergranular, see Fig. 6. 
Introducing an overload prior to the dwell time had a significant influence on the crack growth rate. For an overload of $15 \%$, the dwell time effect was more or less completely extinguished and the crack growth rate was the same as for pure fatigue loading without a dwell time, see Fig. 4. This can partly be explained by reversed plasticity and the zone of compressive stress which is formed at the crack tip after the partial unloading [15]. It is not obvious whether the decrease in crack growth rate is only due to a reduction of the crack driving force, or if the embrittlement effect of the material is also reduced, e.g. by a reduction of the diffusion rate of oxygen at the crack tip.

Our observation that the fracture appearance changed from intergranular to transgranular with an increasing overload level indicate that the embrittlement effect becomes less prominent when overloads are introduced prior to the dwell time, see Fig. 6. The general crack growth behaviour is illustrated in Fig. 5, where the intergranular crack growth of the $2160 \mathrm{~s}$ dwell time sample in Fig. 5 a) can be compared stepwise through the different levels of overloads 2.5, 5.0, and $15 \%$ in Fig. 5 b)-d) to the more transgranular crack growth behaviour of the baseline sample in Fig. 5 e).

The $C_{R}$ parameter successfully captured the transition from intergranular to transgranular fracture with increasing overload. The decrease in $C_{R}$ with overload indicates a 'smoother' or 'straighter' crack path for higher overloads which would be consistent with an increase in transgranular fracture. The smoother crack path, caused by overloads, would also mean that the crack changes from mode II cracking to predominantly mode I. Antunes et al.[22] have previously reported, for an alloy with $15 \mu \mathrm{m}$ grain size, that a change in fracture behaviour, from intergranular to transgranular, was accompanied 
by a change in $R a$ on the fracture surface from $\sim 9 \mu \mathrm{m}$ for intergranular to $3-5 \mu \mathrm{m}$ for varying degrees of transgranular fracture. The exact value of the point of transition depends on the chosen cut-off wavelength; here the transition occurs around 8-10 $\mu \mathrm{m}$ for the unfiltered $C_{R}$.

The $\lambda_{c o}$-dependence of $C_{R}$ also provided information about on which length-scale the studied crack paths differed. Fig. 14 shows how $C_{R}$ depended on the chosen $\lambda_{c o}$. For $\lambda_{c o}$ values in the interval 5-50 $\mu \mathrm{m}$, the $C_{R}$ values from different testing conditions were similar. $\lambda_{c o}$ values $\geq 100 \mu \mathrm{m}$, on the other hand, gave notable differences in $C_{R}$ values between the different testing conditions. Hence, the major difference in crack path morphology, between the studied test conditions, was due to features in the crack path in the order of a few to several hundred microns, which was significantly larger than the grain size of the material.

Another parameter that showed a correlation with the change in fracture mechanism was the mean crack branch length which was high for the $2160 \mathrm{~s}$ dwell time and no or low overloads, but decreased $\sim 50 \%$ for the baseline and high overload tests. An interesting observation would be that the majority of small braches seem to start in the $(\delta)$ phase, since $\delta$ is Nb-rich it could be more prone to oxidation and become more brittle than the $(\gamma)$ matrix which could lead to crack branching that both starts and stops within the delta phases.

The cracks in the baseline and $15 \%$ overload tests mainly grew transgranularly due to severe plastic deformation at the crack tip. The severe plastic deformation also led to significant crack tip blunting and branching in connection to slip bands as evident by the striations in Fig. 12. Blunting 
of the crack tip will impede the crack growth rate since the energy needed to propagate a blunted crack tip is higher compared to a sharp crack tip. Studying the crack tip from the $15 \%$ overload test in higher magnification revealed some tendency for environmental assisted cracking also for this loading condition, see Fig. 15. From the blunted crack tip, a small crack has been formed and small black dots can be seen in front of the crack. Even if the crack in this case grew transgranularly, it showed some similarity with intergranular cracks in, e.g., Fig. 9. Thus, it might be possible that time dependent crack propagation eventually will occur even for higher overloads, especially if the dwell time would have been longer than the 2160 s used in this study. This will be a topic for further studies.

\section{Summary}

Fatigue crack growth testing has been performed on Inconel 718 at $550{ }^{\circ} \mathrm{C}$ with the purpose of investigating the effect of overloads on the dwell time fatigue crack growth. The following conclusions can be drawn from this work:

- There is a significant increase in crack growth rate when dwell times are introduced at the maximum load (0\% overload) in the fatigue cycle. With a dwell time there is also a shift from transgranular to intergranular crack growth.

- When an overload is applied prior to the dwell time, the crack growth rate decreases with increasing overload levels. For an overload of $15 \%$, the dwell time effect is essentially extinguished and the crack growth rate is the same as for pure fatigue loading without dwell time. 
- The decrease in crack growth rate due to an increasing overload is also accompanied by a transition from intergranular to transgranular cracking.

- There is a tendency to develop more, but shorter, crack branches with an increasing overload level. The branching of the crack is often associated with slip bands or with the presence of $\delta$ phase in the microstructure. Furthermore, High overloads lead to significant blunting of the crack tip.

- The roughness of the crack path increases with an increasing crack growth rate. The smoothest crack paths are found for pure fatigue loading and dwell time fatigue tests with the highest overloads. With no or small overloads, there is a significant oscillation of the crack path and the wavelength is typically on a length scale that is larger than the grain size of the material.

- There is a tendency for modus II crack growth during dwell fatigue which is suppressed with the introduction of overloads.

\section{Acknowledgements}

The authors would like to thank Mr. Bo Skoog, Linköping University, for the help with the laboratory work, Agora Materiae, graduate school, Faculty grant SFO-MAT-LiU\#2009-00971, and the project teams at Linköping University, Siemens Industrial Turbomachinery AB and GKN Aerospace Engine Systems for valuable discussions. This research has been funded by the Swedish Energy Agency, Siemens Industrial Turbomachinery AB, GKN 
Aerospace Engine Systems, and the Royal Institute of Technology through the Swedish research program TURBO POWER, the support of which is gratefully acknowledged.

[1] D. Leo Prakash, M. Walsh, D. Maclachlan, A. Korsunsky, International Journal of Fatigue 31 (2009) 1966-1977.

[2] S. Ponnelle, B. Brethes, A. Pineau, European Structural Integrity Society 29 (2002) 257-266.

[3] D. Gustafsson, J. Moverare, S. Johansson, M. Hörnqvist, K. Simonsson, S. Sjöström, B. Sharifimajda, in: Procedia Engineering, volume 2 of 10th International Fatigue Congress, FATIGUE 2010, pp. 1095-1104.

[4] P. Heuler, E. Affeldt, R. J. H. Wanhill, Materialwissenschaft und Werkstofftechnik 34 (2003) 790-796.

[5] J. P. Pédron, A. Pineau, J. P. P. I. Dron, Materials Science and Engineering 56 (1982) 143-156.

[6] D. Gustafsson, J. Moverare, K. Simonsson, S. Johansson, M. Hörnqvist, T. Månsson, S. Sjöström, in: Procedia Engineering, volume 10 of 11th International Conference on the Mechanical Behavior of Materials, ICM11, pp. 2821-2826.

[7] D. Gustafsson, J. J. Moverare, S. Johansson, K. Simonsson, M. Hörnqvist, T. Månsson, S. Sjöström, International Journal of Fatigue 33 (2011) 1461-1469. 
[8] K. Wackermann, U. Krupp, H.-J. Christ, in: ASTM Special Technical Publication, volume 1539 STP of ASTM International Symposium on Creep-Fatigue Interactions: Test Methods and Models, Siegen, Germany, pp. 297-312.

[9] J. J. Moverare, D. Gustafsson, Materials Science and Engineering A 528 (2011) 8660-8670.

[10] K. Obergfell, P. Peralta, R. Martinez, J. Michael, L. Llanes, C. Laird, International Journal of Fatigue 23 (2001) 207-214.

[11] D. J. Morrison, V. Chopra, J. W. Jones, Scripta Metallurgica et Materialia 25 (1991) 1299-1304.

[12] P. Reed, J. King, Scripta Metallurgica et Materialia 26 (1992) 18291834.

[13] R. Rahouadj, J. Menigault, M. Clavel, Materials Science and Engineering 93 (1987) 181-190.

[14] S. Chen, G. Gottstein, Acta metall 36 (1988) 3093-3101.

[15] D. Gustafsson, E. Lundström, International Journal of Fatigue 48 (2013) $178-186$.

[16] I. Gutierrez-Urrutia, S. Zaefferer, D. Raabe, Scripta Materialia 61 (2009) $737-740$.

[17] D. A. Woodford, Energy Materials: Materials Science and Engineering for Energy Systems 1 (2006) 59-79. 
[18] U. Krupp, International Materials Reviews 50 (2005) 83-97.

[19] E.-G. Wagenhuber, V. B. Trindade, U. Krupp, in: L. E.A. (Ed.), Proceedings of the International Symposium on Superalloys and Various Derivatives, 6th International Symposium on Superalloys 718, 625, 706 and Derivatives, Pitsburg, U.S., pp. 591-600.

[20] L. Viskari, M. Hörnqvist, K. L. Moore, Y. Cao, K. Stiller, Acta Materialia 61 (2013) 3630-3639.

[21] M. Gao, D. J. Dwyer, R. P. Wei, in: Superalloys 718, 625, 706 and Various Derivatives, pp. 581-592.

[22] F. V. Antunes, A. Ramalho, J. M. Ferreira, International Journal of Fatigue 22 (2000) 781-788. 
Table 1: Composition of elements for Inconel 718.

\begin{tabular}{ccccccccccccccc}
\hline Alloy & Wt \% & $\mathrm{Ni}$ & $\mathrm{Cr}$ & $\mathrm{Fe}$ & $\mathrm{Mo}$ & $\mathrm{Nb}$ & $\mathrm{Co}$ & $\mathrm{C}$ & $\mathrm{Mn}$ & $\mathrm{Si}$ & $\mathrm{S}$ & $\mathrm{Cu}$ & $\mathrm{Al}$ & $\mathrm{Ti}$ \\
\hline \multirow{2}{*}{ Inconel 718 } & Min. & 50 & 17 & & 2.8 & 4.75 & & & & & & & 0.2 & 0.7 \\
& Max. & 55 & 21 & balance & 3.3 & 5.5 & 1 & 0.08 & 0.35 & 0.35 & 0.01 & 0.3 & 0.8 & 1.15 \\
\hline
\end{tabular}




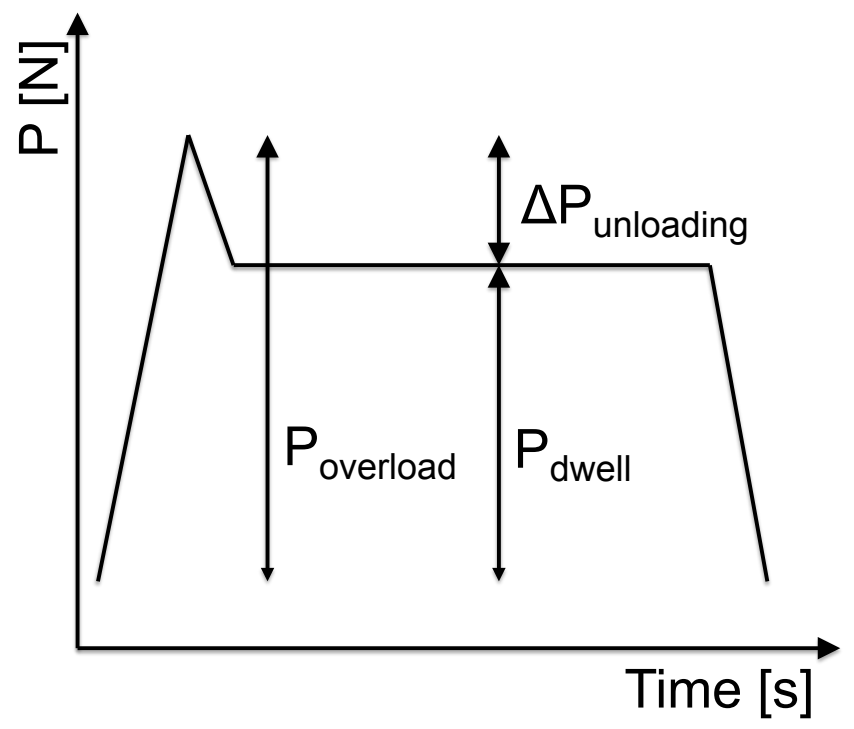

Figure 1: The overload cycle. 


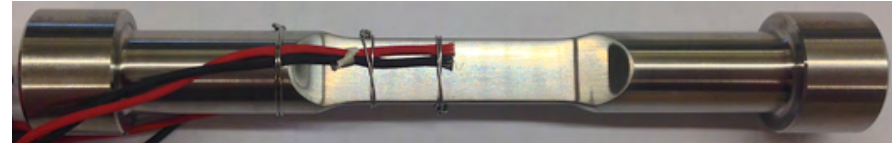

Figure 2: Instrumented Kb-type test specimen used for all tests. 

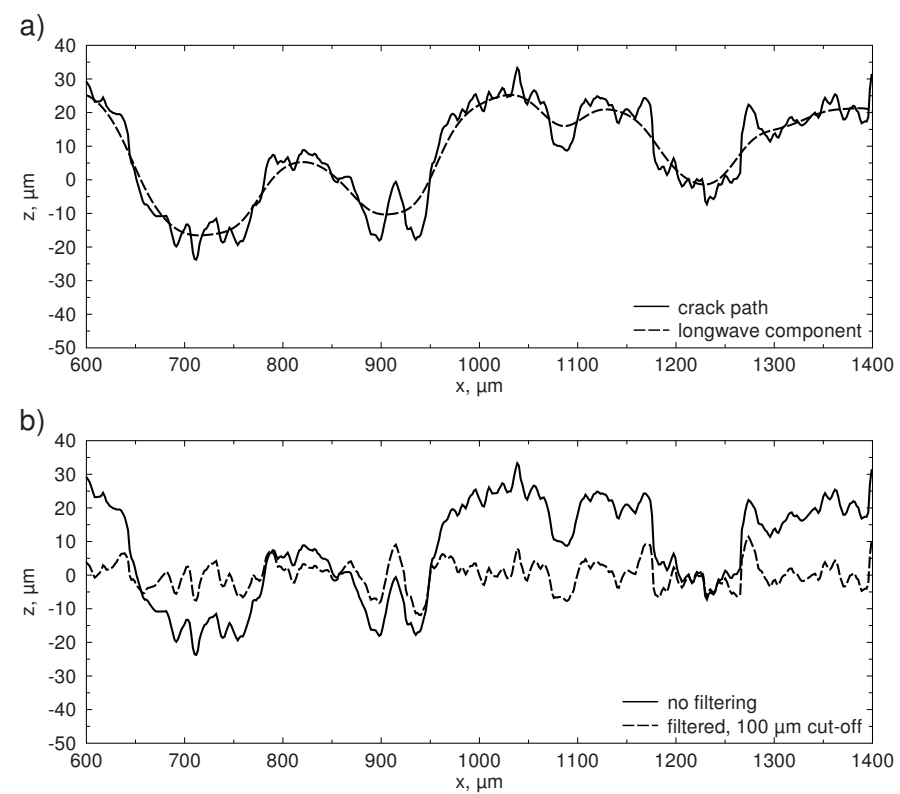

Figure 3: Filtering of the crack path. a) The unfiltered crack path and the longwave component of the crack. b) An unfilltered crack and a filtered using $100 \mu \mathrm{m}$ cut-off. 


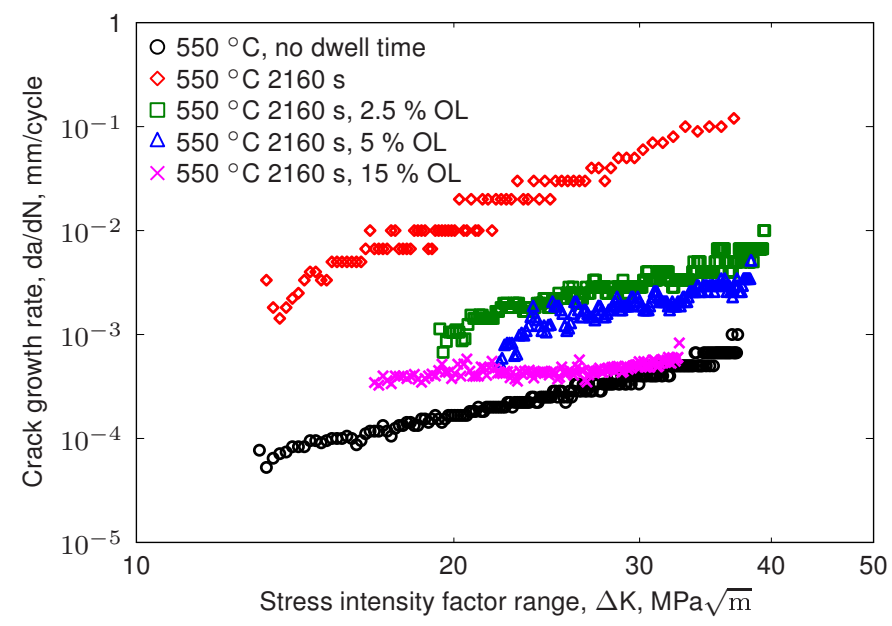

Figure 4: Crack growth rate for the different fatigue conditions. 

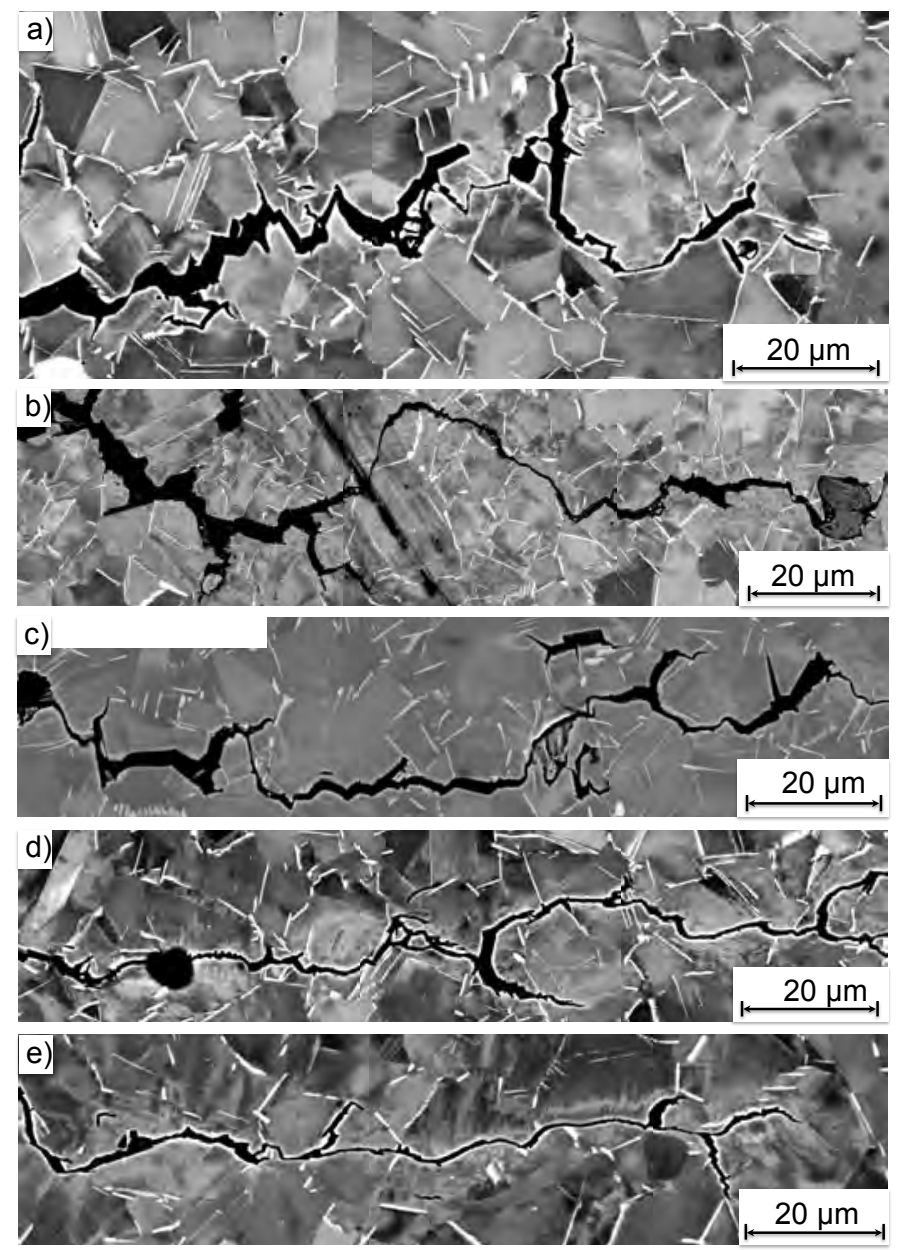

Figure 5: General crack growth behaviour at $550{ }^{\circ} \mathrm{C}$ for: a) $2160 \mathrm{~s}$ dwell time, b) $2.5 \%$ overload crack, c) $5.0 \%$ overload crack, d) $15 \%$ overload, and e) baseline. 

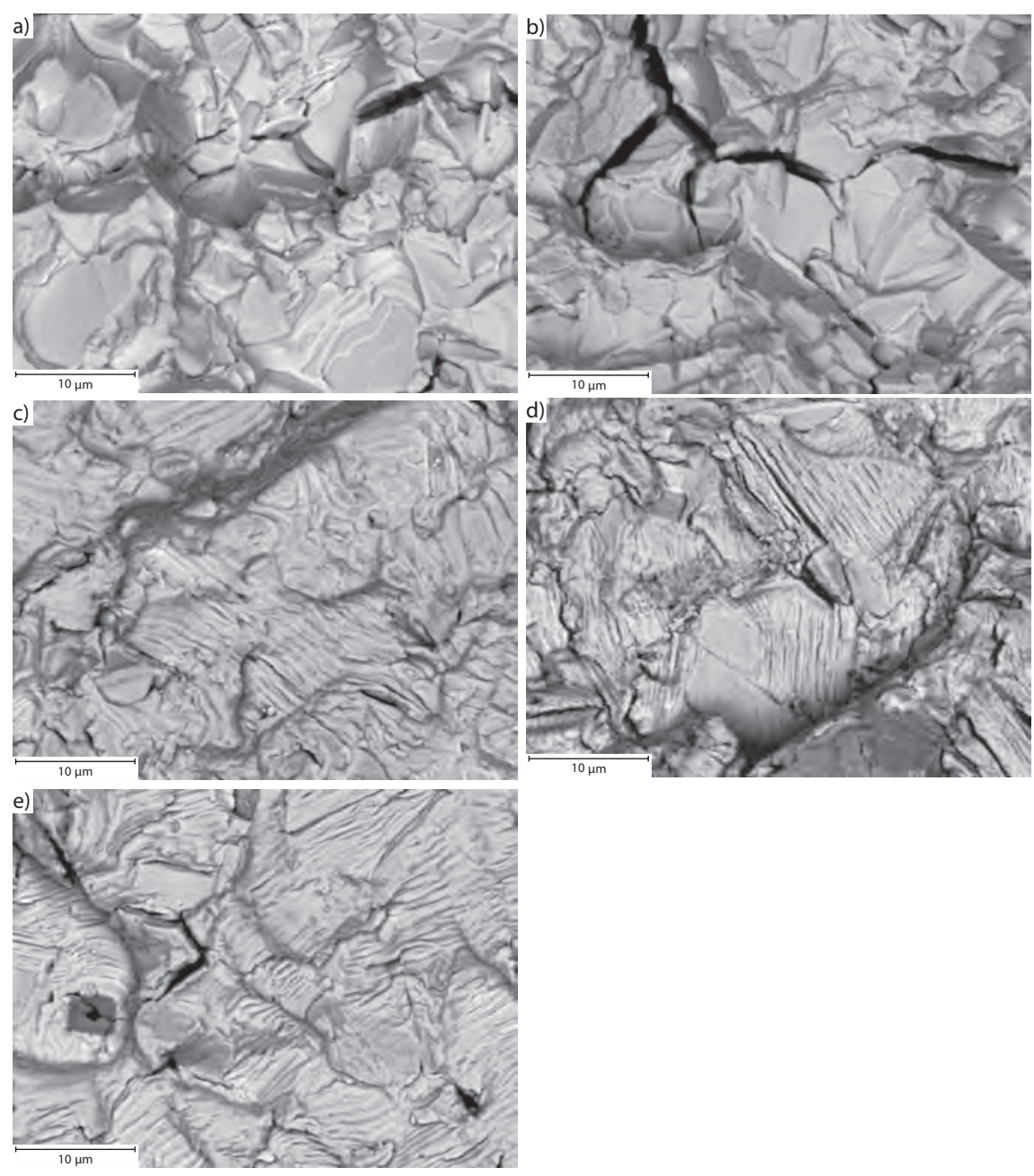

Figure 6: Fracture surfaces from fatigue tests: a) $2160 \mathrm{~s}$ dwell time, b) $2.5 \%$ overload, c) $5 \%$ overload, d) $15 \%$ overload, and e) baseline. 


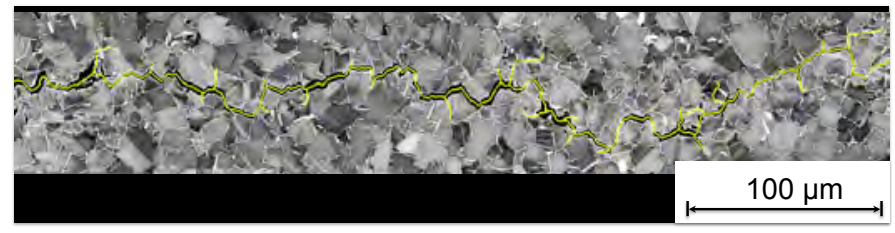

Figure 7: Crack length measurement including branching for the $2160 \mathrm{~s}$ dwell time test at $550{ }^{\circ} \mathrm{C}$. 
a)

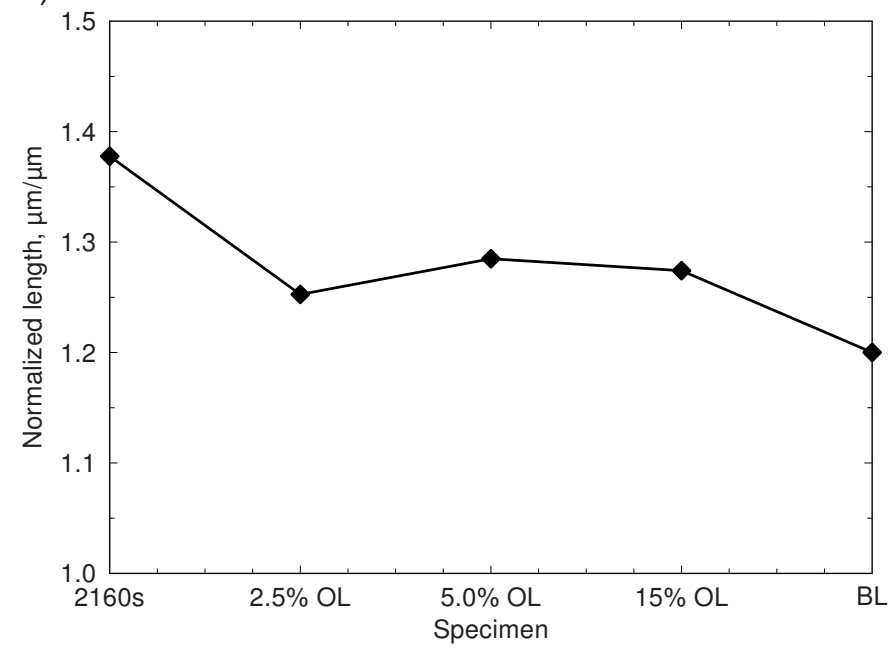

b)

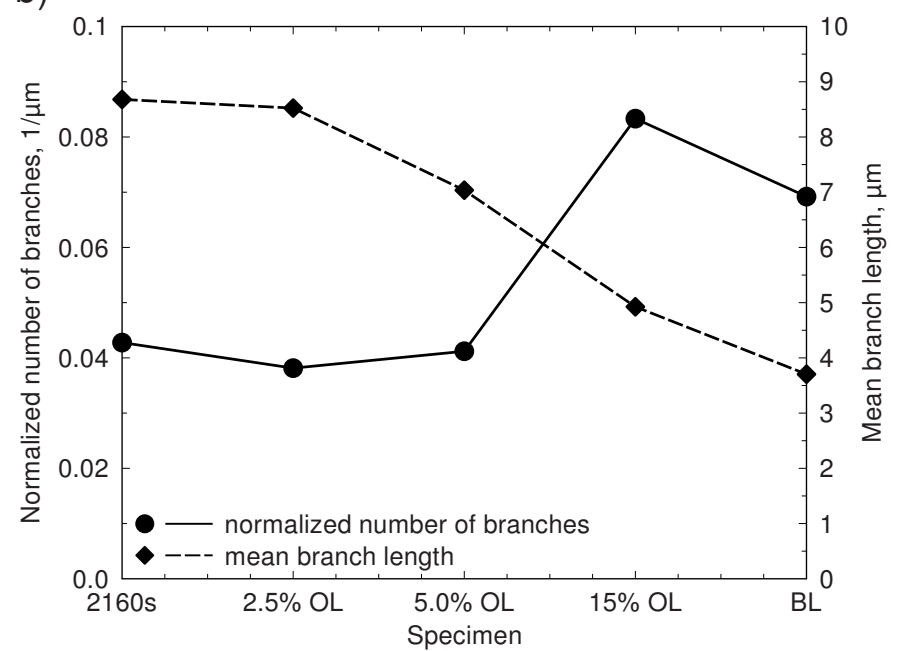

c)

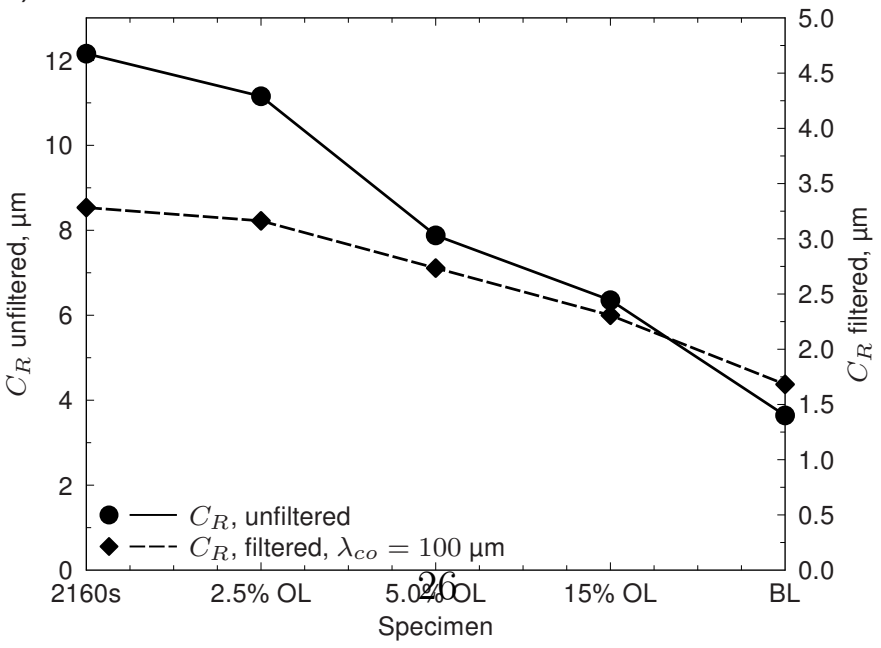

Figure 8: Crack path parameters: a) Normalized main crack length, b) normalized number of crack branches and mean branch length, and c) crack roughness, $C_{R}$. 


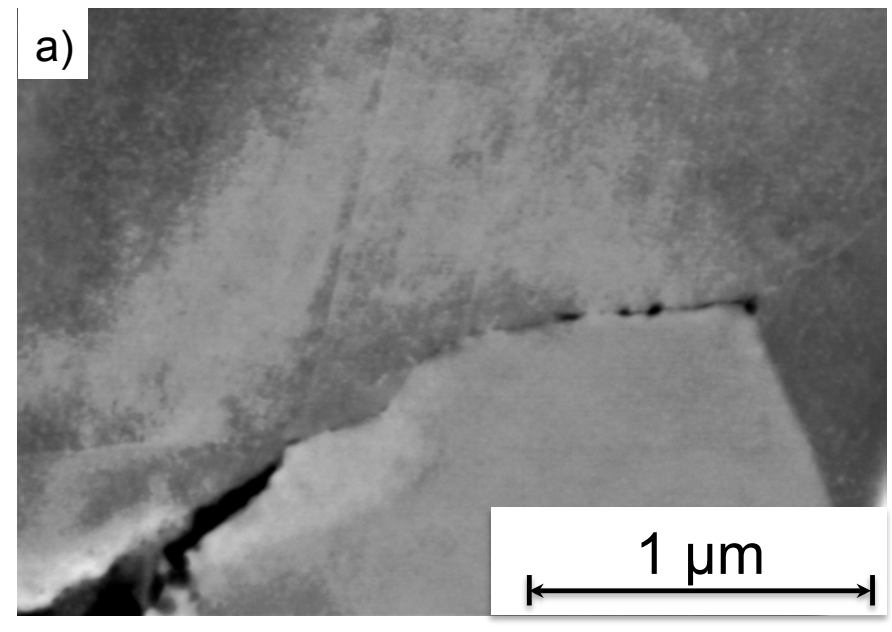

b)

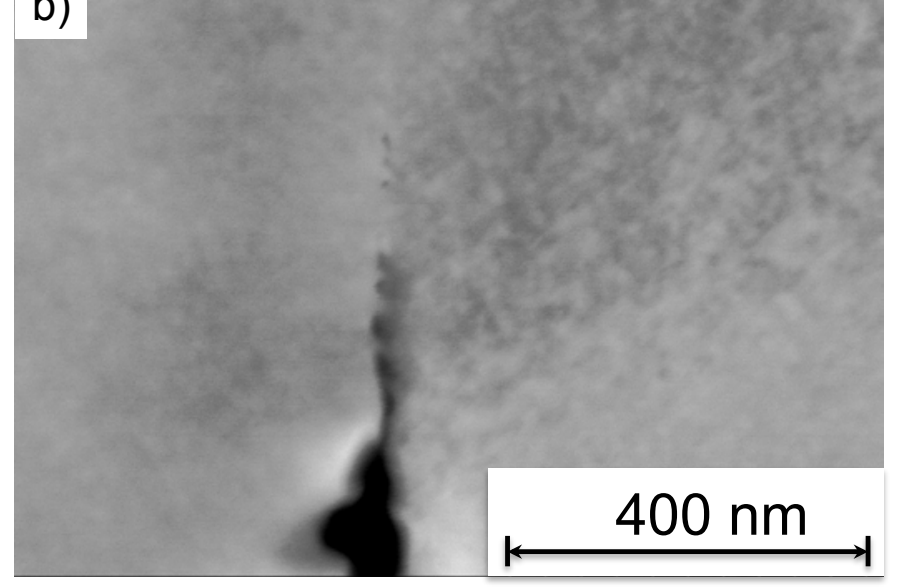

Figure 9: The $2.5 \%$ overload sample showing: a) Growth of pores in grainboundaries and, b) intergranular fracture by growth of nano-sized pores. 

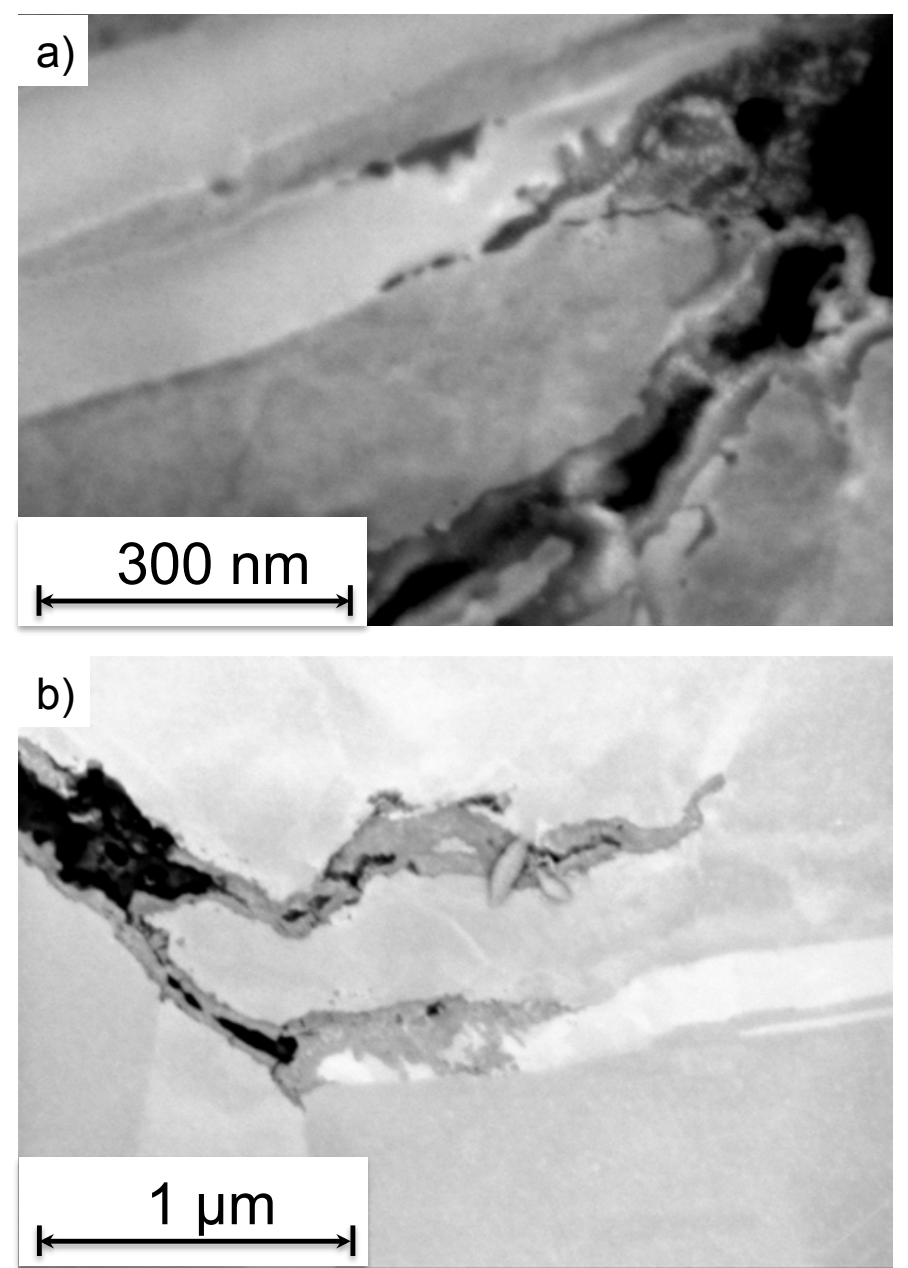

Figure 10: Secondary electron images of $2.5 \%$ overload, crack growth in connection to $\delta$ phase with oxidation. 


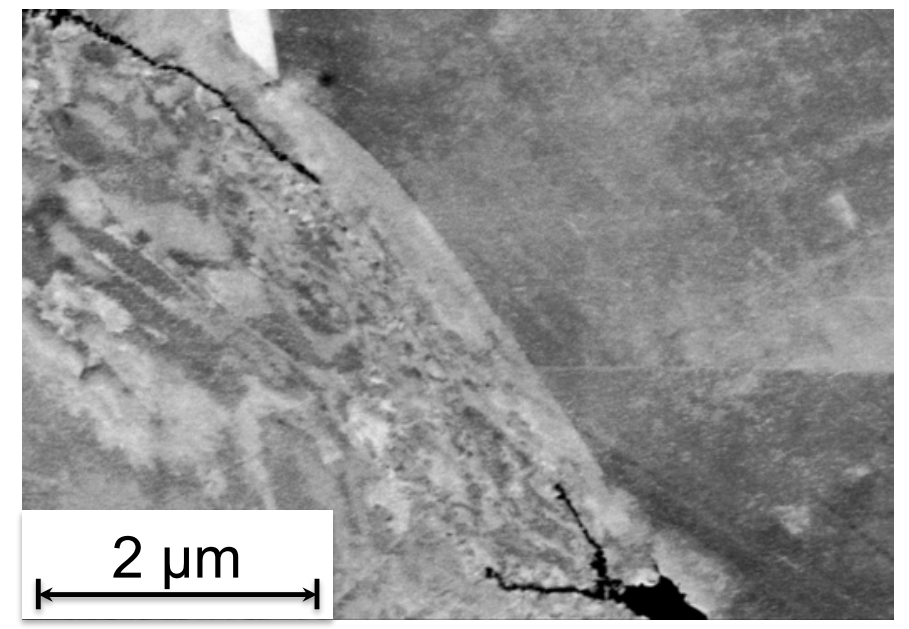

Figure 11: Crack growth in an area subjected to severe local plastic deformation. 

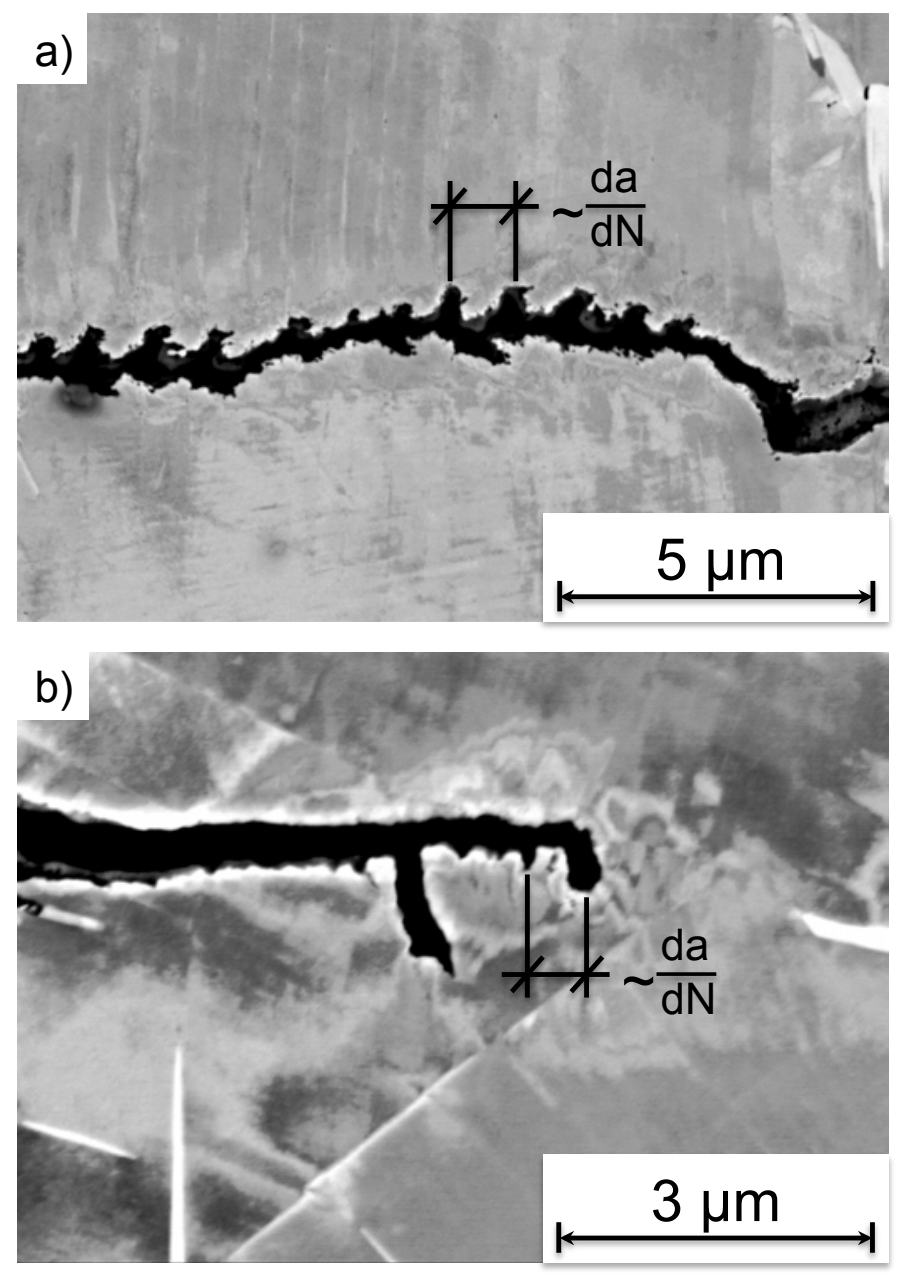

Figure 12: The $15 \%$ overload sample roughly showing the distance corresponding to one overload cycle and: a) A serrated crack path and, b) the blunted crack tip. 


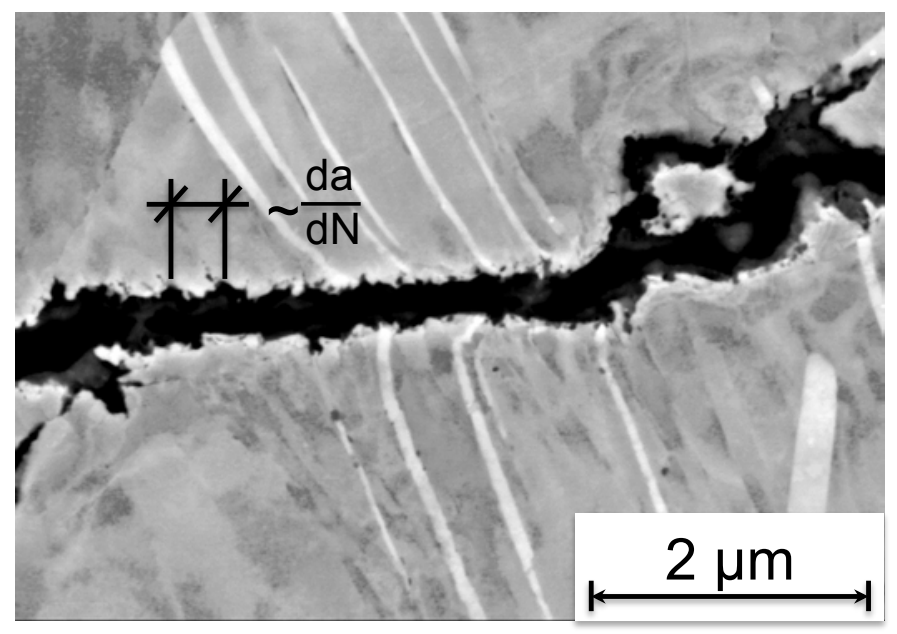

Figure 13: The $15 \%$ overload sample showing transgranular cracking through $\delta$ phases. 


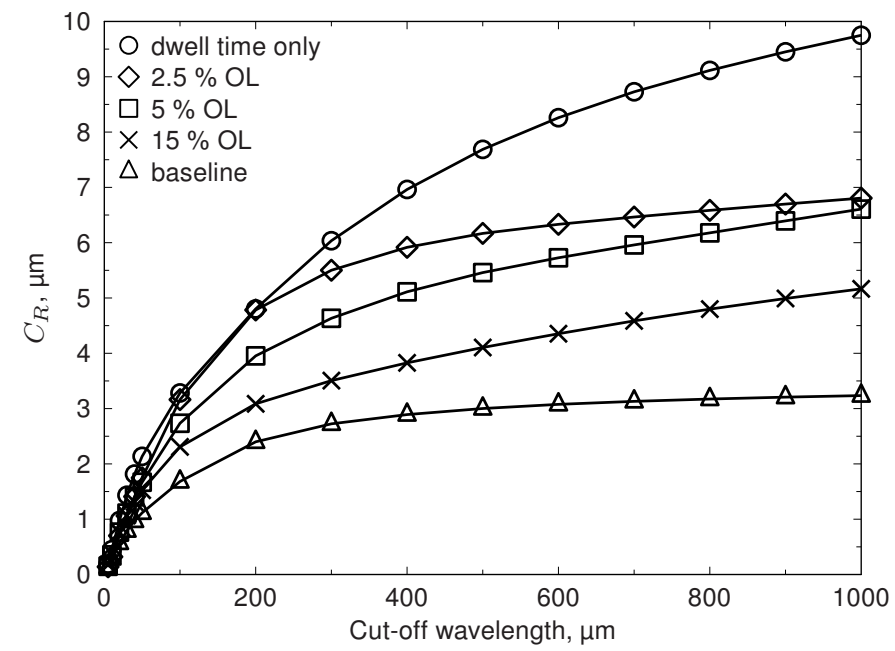

Figure 14: The influence of chosen cut-off wavelength on the crack roughness $C_{R}$. 


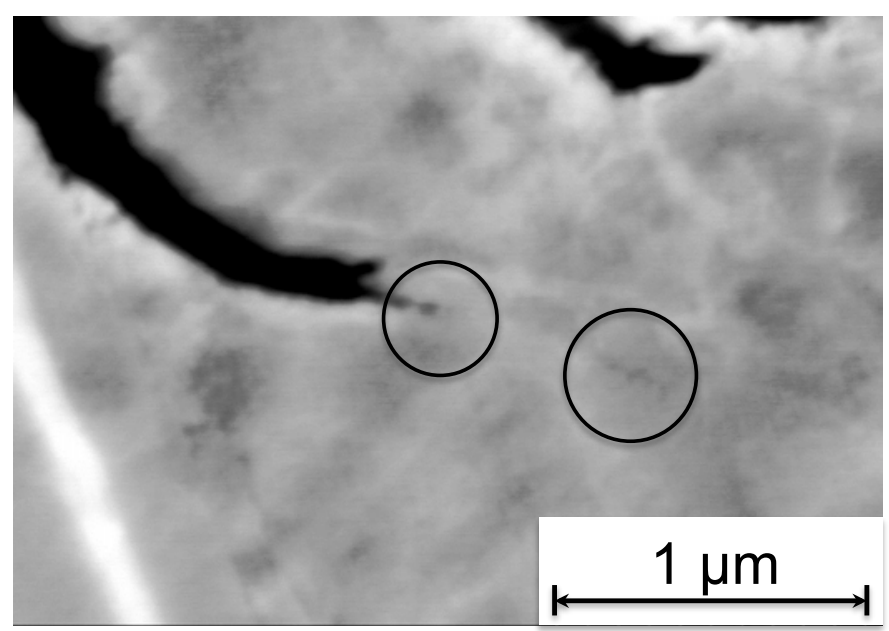

Figure 15: Crack growth in the severely plasticized material neer the crack tip can be seen as small black dots in front of the crack. 